\title{
СТАНОВЛЕНИЕ СИНЕРГЕТИЧЕСКОЙ МЕТОДОЛОГИИ КАК АКТУАЛЬНАЯ КУЛЬТУРОЛОГИЧЕСКАЯ ПРОБЛЕМА
}

\section{И.А. Донникова}

Современная наука претерпевает кардинальные методологические изменения, вызванные формированием новой научной парадигмы и соответствующей ей картины мира. Несмотря на то, что складывающаяся парадигма еще не получила определенного обозначения (ее называют постнеклассической, синергетической, эволюционной), все исследователи единодушны в определении сущности научных трансформаций. Суть их заключается в выявлении и обосновании закономерностей развития открытого, нелинейного, самоорганизующегося мира, структурными элементами которого являются и человек, и общество. Складывающаяся на основе принципов теории самоорганизации методологическая программа обретает универсальный характер, определяя единые исследовательские подходы в различных областях научного знания и выделяя в названии новейшего научного направления - синергетики - еще один смысловой аспект - взаимодействие различных направлений науки на основе единой методологии.

Действительно, принципы самоорганизации, разработка которых берет начало в термодинамике неравновесных систем, сегодня находят применение в социологических, исторических, политологических, экономических, лингвистических и других исследованиях. Предметное поле синергетики продолжает расширяться, формируя исследовательские программы в казалось бы очень далеких от теории самоорганизации научных отраслях. Так, в одной из своих совместных работ Е.Н.Князева и С.П.Курдюмов, рассуждая о высокой нелинейности

Актуальні проблеми духовності 
человека, исследуют возможность применения синергетической методологии к комплексному анализу человека, его мышления, памяти, познания, творчества и других характеристик [4]. К различным аспектам применения принципов синергетики в социально-гуманитарном знании обращаются Л.Д.Бевзенко, Л.С.Горбунова, И.С.Добронравова, И.С.Ершова-Бабенко, В.С. Лутай, И.В.Предборская, А.В. Чалый и др. Предметом новейших научных разработок становятся различные «человекоразмерные» объекты (В.С.Степин), поэтому так плодотворно сотрудничество синергетики с социально-гуманитарными науками.

В набирающем силу научном полилоге явно ощущается дефицит культурологических исследований, несмотря на то, что культура представляет собой, пожалуй, один из самых «человекоразмерных» объектов. При этом речь не идет только о стремлении следовать научным нововведениям (хотя и само это стремление может быть конструктивным). Вполне понятна и обоснована позиция исследователей, которые с определенной долей скептицизма оценивают «триумфальное шествие» синергетической методологии в гуманитарном знании, сопровождающееся ее философской интерпретацией. В частности, С.П. Капица, С.П. Курдюмов, Г.Г. Малинецкий в работе «Синергетика и прогнозы будущего» отмечают: «Ни кибернетика, ни квантовая механика, ни синергетика не являются, собственно, философскими теориями или подходами. Их философские интерпретации могут быть интересны и даже полезны. Однако важно отделять конкретные результаты от их осмысления... Размышления И.Пригожина о развитии естествознания, концепция универсального эволюционизма, выдвинутая Н.Н. Моисеевым, которые опираются на результаты конкретных исследований, не должны создавать обманчивого ощущения легкости и простоты философского анализа созданной научной картины мира» [3].

Мы согласны с тем, что использование идей синергетики в гуманитарном знании, и в частности, культурологическом, оправдано в том случае, когда исследуемый феномен действительно проявляет себя нелинейно, когда его различные состояния могут быть описаны синергетическими категориями. Иными словами, применение нового подхода должно быть аргументированным и обоснованным. Предпосылки внедрения синергетического подхода в культурологическом знании и станут предметом нашего рассмотрения.

Следует отметить, что еще в 90-е годы ушедшего столетия обсуждалась возможность применения принципов синергетики в культурологии. Так, М.С. Каган в заключительном разделе «Философии культуры», рассматривая методологические принципы изучения истории 
культуры, обращается и к основным идеям синергетики. Обсуждая их продуктивность в сфере гуманитарного знания, он указывает и на границы применения синергетического подхода: «В той мере, в какой изучение человека, общества, культуры стремится быть научным при всей специфичности гуманитарного знания, - оно должно освоить методологию современного изучения природных систем, но поскольку они являются менее сложными, чем системы антропо-социо-культурные, методологические принципы их изучения, сложившиеся на почве изучения физических, химических, биологических систем, с органичным для них математическим аппаратом, должны быть приведены в соответствие с уровнем сложности данного класса систем, а не переноситься механически из сферы естествознания в сферу гуманитарного знания» [2, с. 32].

Подобную методологическую осторожность разделяют многие исследователи культуры, которые, если и допускают применение синергетического подхода, то очень дозировано. Так, авторы энциклопедии «Культурология. ХХ век» в одной из статей отмечают: «Если целый класс исторических тенденций социокультурной динамики (например, циклические изменения в экономике, катастрофы в политике, взрывы в культуре и др.) может быть подвергнут плодотворному анализу с позиций теории синергетики, то изучение особенностей изменений в искусстве, явлений обыденной жизни, внутренних закономерностей индивидуального развития человека с этих позиций далеко не всегда может быть плодотворным» [6, с. 136].

В работе Л.Д.Бевзенко «Социальная самоорганизация. Синергетическая парадигма: возможности социальных интерпретаций» культура рассматривается в качестве одного из механизмов самоорганизационных процессов, создающего зоны социальной упорядоченности: «Локальная ценностная, нормативная, семантическая, символическая среда, процедуры инициации - основные культурные механизмы, обеспечивающие локальность аттрактивной структуры» [1, с. 226]. Понимая под культурой пространство смыслов и значений, автор включает ее в самоорганизационные процессы в социуме, которые не исчерпываются, однако, только культурными механизмами. Социальная самоорганизация, по мнению Л.Д. Бевзенко, включает собственно социальное («социумное»), культурное и психологическое. Поскольку автор обращается скорее к социологическим аспектам социальной самоорганизации, понятна и отводимая культуре роль - как одной из ее составляющих, хотя, на наш взгляд, возможны более широкие интерпретации самоорганизационных процессов в социуме. Тем не менее, обоснова- 
ние того, что культура связана с процессами социальной самоорганизации, уже обладает гносеологической ценностью и эта идея должна получить дальнейшее развитие.

Продуктивным для разработки синергетического подхода к культуре является предложенное С.Б. Крымским понимание ее как «актуализации смыслового потенциала творческой деятельности» [5, с. 56]. Культура создает ценностно-смысловой универсум человека, в котором естественная экология переходит в культурную онтологию человечества - называемую цивилизацией [5, с. 28]. Такое понимание культуры, на наш взгляд, универсализирует ее сущность и дает основания определять культуру более широко - как способ самоорганизации человеческого бытия.

Следует отметить, что соотнесение культуры с самоорганизационными процессами не является абсолютно новой постановкой проблемы. В 1992 году этот подход был изложен в статье А.Н. Свидзинского «Культура как феномен самоорганизации». Используя одну из главных идей синергетики - согласованности эволюционных процессов в природных и социальных системах, а также опираясь на идеи Т.де Шардена и В.И. Вернадского, автор определяет культуру как процесс самоорганизации ноосферы. K сожалению, предложенный подход не получил дальнейшего развития в отечественной культурологии, видимо, по причине, на которую указывает сам А.Н. Свидзинский- слишком укоренилось и в науке, и в обыденном сознании представление о культуре как системе артефактов, т. е. продуктов творческой деятельности человека. А это создает своеобразный «замкнутый круг» культурологических проблем, поскольку, с одной стороны, культура - это творческий процесс, а с другой - набор завершенных, а потому статичных по своей природе плодов творчества. Каково их функционирование в «настоящем» и «будущем» культуры, как они включаются в процесс жизнетворчества людей, как соотносятся с творческой сущностью культуры? Трудно не согласиться с А.Н. Свидзинским, который отмечает, что анализ этих и подобных проблем возможен только в случае, «если вместо аматорского, поверхностного понимания культуры как объекта опеки соответствующего министерства, мы построим концепцию культуры, соответствующую уровню современной науки о мире и об общих законах его развития» [7, с.142].

Если оставаться в границах «артефактного» понимания культуры, действительно, не возникает необходимости менять подходы к ее исследованию. А если такие попытки и предпринимаются, они принципиально ничего не меняют в понимании сути исследуемого явления, 
поскольку исходят из той же системы артефактов, но представленной в ином ракурсе. В результате культура, несмотря на солидный возраст культурологического знания, остается понятием размытым, нечетко обозначенным и, в общем, не вполне понятным. Сегодня насчитывается свыше тысячи определений культуры, и видимо, количество их будет расти, если продолжать двигаться в том же направлении - объяснять сущность культуры, исходя только из результатов человеческой деятельности, и не затрагивать вопросы, почему и для чего эти результаты возникают.

В контексте парадигмальных научных изменений становится очевидным, что культурологическое знание должно расстаться с традиционными подходами. Смена методологии призвана изменить и содержание культурологического знания, которое сегодня, по сути, остается историко-культурологическим, изучающим многочисленные культурные артефакты. Поскольку речь идет о формировании новой, синергетической методологии, культурология в содержательном плане должна стать «философичнее», пополниться солидным объемом теоретического материала, раскрывающим сущность культуры, ее содержание, функции с позиций единого подхода и с этих же позиций анализирующего мировой историко-культурный процесс. (Показательно в этом плане содержание вузовских учебников по культурологии, которые в большинстве своем являются учебниками по истории культуры).

Нам представляется, что присущий культурологическому знанию плюрализм подходов и концепций становится плодотворным в контексте синергетической парадигмы, позволяет подняться на более высокий уровень его систематизации и обобщения. В современной философии культура предстает чрезвычайно сложным феноменом, включающим качественно различные явления, процессы и состояния человеческой жизни. В своем качественном разнообразии культура охватывает все индивидуально-личностные проявления человека (от интимно-телесных до духовно-интеллектуальньг и практических), широчайший спектр межличностных и коллективных взаимодействий, а также включает и природу в той мере, в какой она детерминирует социокультурные процессы.

Любые отношения, возникающие в системе «природа-человек-общество» могут стать объектом культурологических интерпретаций. При этом на уровне многочисленных артефактов культуры видимым остается только социокультурный «хаос». Внутреннее единство, организующие и регулирующие механизмы человеческого бытия выявляются при переходе к более высокому уровню осмысления социокуль- 
турной реальности. Объяснить, как возникает, функционирует и эволюционизирует целостное природно-социо-культурное бытие человека возможно, переходя от социокультурного «хаоса» (культурных артефактов) к социокультурному порядку (самоорганизующемуся бытию человека).

С позиций синергетики культура может быть представлена как специфический механизм (способ) самоорганизации жизни людей, детерминирующий человеческое существование, направляющий его в русло творчества, развития, самосохранения через осмысленное отношение человека к миру. Применение синергетического подхода заключается в том, что культура рассматривается как присущий исключительно человеку способ жизненной организации, который эволюционизирует по синергетическим «правилам». Понимание культуры как способа социальной самоорганизации, позволяет «ввести» ее в социальный контекст, не замыкать культуру на собственном содержании и, что не менее важно, через активность человека «вывести» из культуры саму социальную реальность.

При таком подходе на первый план выходит не содержание культуры в его «артефактном» выражении, а ее функциональная направленность, позволяющая сосредоточить внимание на процессе возникновения и развития социокультурной реальности, социального порядка. В рамках синергетического подхода культура важна не столько результатами, которые можно знать или не знать и при этом принципиально ничего не меняется в человеческой жизни. Важным становится ее самоорганизационный потенциал, то, без чего жизнь перестает быть человеческой по своей сущности.

Если под самоорганизацией понимать процессы самопроизвольного возникновения, относительно устойчивого существования и саморазрушения упорядоченных структур в открытых, нелинейных системах и исходить из того, что они присущи и природным, и социальным системам, то возникает необходимость в выявлении специфики этих процессов в различных системах. В системе человеческого бытия самоорганизационные (негэнтропийные) процессы следует связывать с культурой.

Понимая, что в познании уже укрепилось определенное значение категорий «социум», «социальный», тем не менее, уточним, что понятие «социальная самоорганизация» лишено в данном случае узкого социологического аспекта. Под социальной самоорганизацией нами понимаются процессы саморегуляции и самоупорядочивания в системе «человек-общество-природа». Рассматривая процессы социальной 
самоорганизации, мы исходим из того, что бытие человека социально и культурогенно, и таково оно вследствие реализации самоорганизационных потенций культуры.

В рамках одной статьи не представляется возможным проанализировать основные культурологические подходы с целью выявления в них предпосылок синергетического анализа. Тем не менее позволим себе утверждать, что при соответствующем изменении ракурса рассмотрения в любой культурологической теории достаточно легко выявляются самоорганизационные потенции культуры, идет ли речь о знаково-символической, игровой, деятельностной, ценностной, диалогической, психологической и других концепциях. По сути авторы и сторонники того или иного подхода акцентируют внимание на вполне определенных механизмах функционирования культуры, связывая их с ее семантическим строем, или ценностным содержанием, или технологиями деятельности человека. Синергетический подход дает возможность синтезировать разные аспекты этого сложного феномена, определяя назначение культуры через понятие самоорганизации. C позиций синергетического подхода полифункциональность культуры обретает направленность в виде вектора негэнтропии, сдерживания деструктивньг в своей сущности явлений и процессов, сопровождающих социальную эволюцию. Культура создает и структурирует бытие человека как целостный духовно-предметный мир.

Соотнесение культуры с негэнтропийными процессами в социуме позволяет акцентировать внимание, прежде всего, на ее информационной (смысловой составляющей). Именно смыслопорождающие потенции культуры обуславливают ее востребованность в качестве способа самоорганизации человеческого бытия. Смысл, рождаясь на границе субъективного и объективного мира, есть выражение присутствия человека в мире. Пронизанный информационными потоками материальный мир, чуждый в своей объективности и хаотичности человеку, обретает структурированность, комфортность, ценностную значимость через смысл, рождаемый в культуре. Благодаря культуре человек живет в искусственно комфортном мире, защищенным от всего непонятного, тревожного, пугающе-таинственного, по определению С.Б. Крымского, - в ценностно-смысловом Универсуме культуры [5, c. 26].

Связь «человек-смысл-культура», на наш взгляд, может раскрыть сущность социалъной самоорганизации, стать основой для культурологических интерпретаций основных понятий синергетики, таких как бифуркация, аттракторы, энтропия, информация и др. 
Поскольку культура - феномен многомерный и сверхсложный, ее различные сферы и подуровни могут быть представлены как самоорганизационные структуры, интерпретированы как социокультурные аттракторы или бифуркационные области социокультурной реальности. Так, аттракторы распознаются и в архетипических установках человеческой психики, и в ценностном строе культуры, и в культурных традициях, и в языковых конструкциях, поскольку являются формами преодоления хаоса и установления порядка в определенной сфере социальной реальности. Переломные этапы истории, периоды научных революций, политических или экономических кризисов, смена мировоззренческих систем и т.д. могут быть представлены как бифуркационные области в нелинейной социокультурной динамике-области интенсивных взаимодействий, в которых благодаря действию культурных механизмов рождаются новые локальные структуры, качественно новые целостности.

Культура рождает и поддерживает порядок на всех уровнях человеческого бытия. Собственно, утвердившиеся в социальном познании многочисленные обозначения сфер культуры и человеческой деятельности, такие как «политическая культура», «экологическая культура», «нравственная культура» и т.д., не только выделяют ту или иную область социокультурного бытия, но и указывают на творческую направленность человеческой деятельности в данной сфере, дающей негэнтропийный эффект. Именно это, видимо, и отличает, например, деятельность в сфере производства или искусства от, соответственно, культуры производства и художественной культуры.

Предлагаемый подход не только не противоречит устоявшимся представлениям о сущности культуры, но позволяет раскрыть новые грани этого сложного явления, найти дополнительные обоснования имманентности культуры и бытия человека. Синергетический подход дает возможность акцентировать внимание на культурологических проблемах, которые либо не получили должной разработки либо вообще игнорировались предшествующей парадигмой.

В частности, возникает возможность упорядочить и систематизировать различные подходы к культуре, которые часто презентуют диаметрально противоположные точки зрения. Так, с одной стороны, культура - лишь одна из многих составляющих человеческой жизни, «отвечающая» за духовность, гуманность, творчество и т.д., с другой - соотносится со всем ее содержанием. И первый, и второй подход мало конструктивны в объяснении сущности и назначения культуры. Первый - поскольку «сужает» культуру до одной из сфер социаль- 
ной действительности, до набора артефактов, о чем уже говорилось. $\mathrm{C}$ позиций же второго подхода в содержание культуры включаются, напротив, все социальные явления, в том числе и деструктивные, энтропийные по сути (отсюда - семантические нонсенсы типа «уголовная культура», или отношение к ненормативной лексике как составляющей культуры речи). Неясна и гносеологическая роль категории культуры, поскольку она вполне заменяема другими понятиями и лишается самостоятельного статуса. Понятия культуры и общества, по сути, не разделяются, история человечества становится историей культуры, включая все проявления человеческой (в том числе и «нечеловеческой) активности - войны, культы вождей, политические интриги, акты вандализма и пр. Аналогичная взаимозаменяемость имеет место и в использовании понятий «культура» и «цивилизация».

Синергетический подход к культуре может стать своеобразной «бритвой Оккама», устанавливая соотношение между понятиями «общество», «культура», «цивилизация», которое традиционно рассматривалось как отношение между целым и его частями, где в качестве целого выступало общество, а культура (и цивилизация), соответственно его части. Синергетика устанавливает качественно новый «тип» зависимости целого от части и наоборот, которая определяется их ролью в эволюции системы. В этом смысле они могут меняться местами целое выполнять функцию части, а часть - выступать в роли целого, становясь «эпицентром» нелинейной эволюции и рождая новую целостность. В самоорганизующемся мире подходы формальной логики, «выводящей» целое из части и наоборот, недейственны. «Классический линейный принцип суперпозиции теряет свою силу в сложном и нелинейном мире... Целое не равно сумме частей. Вообще говоря, оно ни больше, ни меньше суммы частей. Оно качественно иное по сравнению с частями, которые в него интегрированы. И, кроме того, формирующееся целое видоизменяет части. Коэволюция различных систем означает трансформацию всех подсистем посредством механизмов установления когерентной связи и взаимного согласования параметров их эволюции» [4].

Традиционное понимание культуры (или цивилизации) как части социального бытия с позиций новой методологии мало конструктивно для объяснения социальной эволюции. Культура «ограничена» не сферами социума, а только набором своих функций, детерминированных ее негэнтропийной сущностью. В этом смысле культура не может быть энтропийна, но не может «быть» или «не быть» в определенных сферах социального бытия. 
Еще одну проблему, которая просматривается за множеством подходов к культуре, можно сформулировать как проблему целостности культуры. Рассматривая культуру как целостное, духовно-материальное образование, большинство исследователей, тем не менее, смещают акценты на ее духовную составляющую, а материальную чаще именуют как «цивилизация». Деление культуры на духовную и материальную порождает множество теоретических проблем, связанных с поиском оснований ее целостности. А в социальной практике решается вечная дилемма: чему отдать предпочтение - пропаганде духовных ценностей или сначала все-таки дать народу материальное благополучие?

Синергетика, обосновывая идею системности, целостности мира, дает возможность обоснования и целостности культуры. Согласно синергетике, самоорганизационные процессы имеют двойственную природу - информационную (применительно к человеческому бытиюсмысловую) и материальную, поскольку сопровождаются возникновением вещественных структур. Как механизм социальной самоорганизации, культура проявляет себя одновременно в виде смыслов (духовной составляющей) и соответствующих форм их выражения (материальной составляющей). Очевидно, взаимообусловленность духовного и материального в культуре, объяснение того, как возникает это гармоничное сочетание, порождающее «архитектуру» социального бытия, и призвано стать предметом философско-культурологических размышлений.

Более того, сам феномен духовности и духовной культуры получает иную интерпретацию. Как правило, дух, духовность связывают с творческим началом, с которым сопряжено зарождение нового, сама возможность изменения и развития. Отвлекаясь от всего многообразия дефиниций, можно отметить, что духу и духовности, отводится функция создания и поддержания миропорядка в целом (религиозная философия, идеалистические философские системы) или социального порядка, в частности, как на макро- (общество в целом), так и на микроуровне (индивидуальное существование). Это дает основания рассматривать духовность как специфический феномен в самоорганизации человеческой жизни.

Духовность предстает главным системообразующим фактором бытия человека, определяющим специфику его самоорганизации, становится базовым условием преодоления социальной энтропии. Возникающая в процессе смысложизненного поиска человека, она представляет собой своеобразный «коридор возможностей» в виде идеалов, ценностей, знаний, идей, которые направляют социальную эволюцию, га- 
рантируют сохранение индивидов, человеческих сообществ, человечества в целом. Коллективный духовный опыт «оседает» в традициях, нормах, различных видах деятельности, воплощается в соответствующих материально-предметных формах, «руководя» жизнедеятельностью целых поколений. Духовность, тем самым, становится одним из проявлений самоорганизационного потенциала культуры. В этом смысле «духовность» противоположна «бездуховности», поскольку последняя является индикатором деградации или распада целостного человеческого бытия вследствие утраты организующих возможностей человеческого духа.

В заключение хотелось бы остановиться еще на одной проблеме, базовой для любых философско-культурологических построений - проблеме антропо-социо-культурогенеза. Поскольку теория самоорганизации базируется на идее коэволюции, нелинейных переходов, рождающих качественно новые системы, она открывает новые перспективы и в объяснении генезиса человека, общества и культуры, который рассматривается как переход природной эволюции в социокультурную.

Среди различных аспектов этой сложной проблемы можно выделить исследование основы, «субстрата», на котором разворачиваются процессы социальной самоорганизации. В качестве такой основы может выступать сознание, представляющее собой особую информационную среду, «таящую» аттракторы культуры. В сложности и многомерности сознания, в синергетическом взаимодействии его составляющих заключена возможность рождения смысла, которая реализуется через систему культурогенных факторов. Подчеркнем, что существующие теории антропо-социо-культурогенеза, акцентирующие внимание на определенных факторах социальной эволюции, комплиментарно взаимодействуют в рамках синергетического подхода. Человек «заявляет» о своем присутствии на земле не одним или несколькими, а системой факторов (через язык, орудия труда, миф, символ, табу и т. д.). Сознание многовекторно выражает себя в культуре, «разворачиваясь» одновременно во многих плоскостях, «материализуясь» в структурах зарождающегося социума. Синергетический подход позволяет проследить, как многомерность сознания воплощается в многомерности культуры, как возникает структурированное информационно-предметное пространство, именуемое социумом.

И последнее. В нелинейном мире необычайно возрастает ответственность индивида за выбор сценариев социального развития. K этим положениям мы бы добавили - наиболее благоприятные социальные сценарии формируются в «силовом поле» культуры. Ответ- 
ственность человека за дальнейшую эволюцию - это ответственность за сохранение и развитие культуры.

\section{1 Литература}

[1] Бевзенко Л.Д. Социальная самоорганизация. Синергетическая парадигма: возможности социальных интерпретаций. - Киев: Ин-т социологии НАНУ, 2002.

[2] Каган М.С. Философия культуры.-СПб.: ТОО ТК «Петрополис», 1996.

[3] Капица С.П., Курдюмов С.П., Малинецкий Г.Г. Синергетика и прогнозы будущего (http://www.futura.ru/index.php3?idart=49)

[4] Князева E.H. Курдюмов С.П. Коэволюция: человек как соучастник коэволюционных процессов (http://srv5.uni-dubna./ru/ journal/view_pub.php?id=5)

[5] Кримсъкий С.Б. Запити філософських смислів. - К.: Вид. ПАРАПАН, 2003.

[6] Культурология. ХХ век. Энциклопедия. Т.2. - 1996.

[7] Свідзінсъкий A.Н. Культура як феномен самоорганізації // Сучасність - 1992. - № 4. - С. 141-155. 